\title{
Structural Correlation of Spectral Domain OCT and Fundus Autofluorescence (FAF) of the Macula, Following Successful Surgical Repair of Rhegmatogenous Retinal Detachment
}

\author{
MARIAM R. FADEL, M.Sc.; SHERIF SHETA, M.D.; ALI M. TAHA, M.D.; HATEM A. SAEED, M.D.; \\ NAHLA B. ABOU HUSSEIN, M.D. and AHMED E. HABIB, M.D.
}

The Department of Ophthalmology, Faculty of Medicine, Cairo University

\begin{abstract}
Background: Macular recovery after surgery for retinal detachment depends on pre-operative and post-operative predictive factors. Pre-operative factors, which influence macular recovery negatively, include duration of macular detachment, height of macular detachment and vitreomacular traction. Post-operative factors, which influence macular recovery negatively, include cystoid macular edema, epiretinal membranes, retinal folds, subretinal Retinal Pigment Epithelium (RPE) migration and persistent subretinal fluid.
\end{abstract}

OCT has elucidated several postoperative factors correlating with poor vision. These features include persistent SRF and increased foveal thickness, demonstrating as well the submacular fluid that couldn't be detected clinically. OCT can detect persistent foveal detachment, distortion and disruption of Outer Retinal Layers (ORLs) and macular folds following successful surgery for RD. FAF has been used to investigate the morphological and functional changes occurring after RD repair.

Objective: The aim of our study is to correlate the structure-function relationship of the macula following successful repair of rhegmatogenous retinal detachment, by correlating the SD-OCT and FAF macular images with BCVA.

Study Design: Prospective observational case series study.

Patients and Methods: Forty-five eyes underwent surgical repair of RRD followed by SD-OCT and FAF imaging one to three months post-operative. SD-OCT and FAF findings were correlated with post-operative BCVA.

Results: Forty-five eyes achieved complete post-operative reattachment with $95.6 \%$ SOSR. The values of BCVA showed significant difference between eyes with the following OCT findings: Macular edema, persistent SRF, RPE-choriocapillaries complex, IS/OS junction disruption and neurosensory detachment and eyes not showing the same OCT changes ( $p$ 0.05).

The values of BCVA showed significant difference between eyes showing hyper-autofluorescence on FAF imaging and eyes not showing hyper-autofluorescence $(p=0.015)$.

Correspondence to: Dr. Mariam R. Fadel, The Department of Ophthalmology, Faculty of Medicine, Cairo University
We found significant association between fundus hyperautofluorescence and the following OCT findings: Macular edema, RPE-choriocapillaries complex irregularity, IS/OS junction disruption and neurosensory detachment.

Conclusion: SD-OCT is considered a valuable tool for evaluating the microstructural changes at the macula. The IS/OS junction disruption, persistent SRF, macular edema, neurosensory detachment and RPE-choriocapillaries complex irregularity are considered vital measures affecting the structure and function of the macula and can explain the incomplete visual recovery despite an anatomical successful RD surgery. Fundus autofluorescence is a non-invasive imaging modality that evaluates the function and health of the photoreceptor and the RPE layers showing great advantage in analyzing the macular function abnormality.

Key Words: SD-OCT - FAF - Rhegmatogenous retinal detachment-Microstructural changes - Maculavisual outcome - Macular edema-IS/OS junction - RPE-choriocapillaries complex - Neurosensory detachment.

\section{Introduction}

IMPORTANT predictors of visual recovery after retinal detachment surgery include preoperative Visual Acuity (VA) and the presence of foveal detachment. Decreased VA after successful repair of retinal detachment may be due to epiretinal membrane, cystoid macular edema, retinal folds, and persistent foveal detachment [1]

Optical Coherence Tomography (OCT) remains an important diagnostic and monitoring tool for all macular diseases and is able to image retinal anatomy essentially to the level of clinical histology. Several studies have shown an association between either the preoperative or post-operative structural changes detected on OCT with post-operative visual outcome after RRD repair [1].

Despite the enormous benefit of OCT in detecting structural abnormalities of the retina postoper- 
atively; however, the functional status of the retina remains difficult to assess [2].

Clinical Autofluorescence (AF) is an imaging modality that is able to evaluate the functional status of the retina, in addition to the anatomy. FAF has been advanced as a superior method due to the high contrast that it provides, identifying areas of RPE loss, measurements of atrophy and its progression [2].

FAF proved its efficacy as a noninvasive diagnostic imaging modality, which can monitor the disease progression and explains visual loss. Moreover, the correlation between the postoperative $\mathrm{AF}$ abnormalities and OCT findings proved to be of great benefit [2]

\section{Patients and Methods}

In Kasr Al-Ainy Hospital, Cairo University; from September 2014 till August 2015; we worked on our prospective observational case series study. Our study included 45 eyes presented with rhegmatogenous retinal detachement, and underwent successful reattachment surgery.

The patients were selected from the Ophthalmology Outpatient Clinic of Kasr Al-Ainy Teaching Hospital. The patients ages ranged from 18 years and older and were given their written informed consent.

\section{The exclusion criteria:}

- Patients with a pre-existing macular pathology such as AMD, macular hole, diabetic maculopathy and traumatic maculopathy.

- Tractional and exudative retinal detachment.

- Recurrence of the detachment.

- Pathological eye disease such as uveitis, glaucoma or retinal vascular occlusive diseases.

- Significant post-operative media opacity interfering with OCT and FAF imaging.

Pre-operatively, all patients underwent complete ophthalmological examination.

The surgical approach was pars plana vitrectomy $(23 \mathrm{G})$.

Phakic patients with any degree of lens opacity or at presbyopic age, underwent phacoemulsification and PCIOL implantation.

Complete routine ophthalmological examination was done on the first week post-operative, then 1 month post-operative.

\section{Post-operative investigations:}

Macular OCT and FAF imaging were done at one to three months intervals post-operative; after stabilizing the retinal reattachment.

For OCT and FAF imaging, we used the TOPCON 3D OCT-2000 FA plus.

\section{- The SD-OCT macular topography was interpreted as follows:}

- Macula: 3D scan: 512 X 128 (128 horizontal scan lines comprised of 512 A-scans), 6 X 6mm.

- Macula: Radial scan: 1024 X 6 or 12 (6 or 12 radial scan lines comprised of 1024 A-scans), $6 \mathrm{~mm}$.

- Retinal thickness map ILM-RPE was measured according to ETDRS.

- The filter used in autofluorescence was the InfraRed SPAIDE FILTER.

- Baseline colored fundus photography and RedFree images were recorded.

Clinically, the macula was defined as the area of retina located between the temporal vascular arcades, approximately $6 \mathrm{~mm}$ in diameter, centered at the fovea. The fovea was defined as the central retinal depression, approximately $4.0 \mathrm{~mm}$ temporal and $0.8 \mathrm{~mm}$ inferior to the center of the optic disc, and was approximately $1.5 \mathrm{~mm}$ in diameter.

Primary outcome parameter: Evaluating the micro-structural and anatomical details of the macula obtained by spectral domain-OCT and fundus autofluorescence and correlating the findings with visual outcome following successful repair of RRD.

Secondary outcome parameter: Correlating the FAF images and SD-OCT findings at the macula following successful anatomically and clinically re-attached retina.

Statistical analysis: Data were coded and entered using the statistical package SPSS. Data was summarized using mean, standard deviation, median minimum and maximum in quantitative data and using frequency (count) and relative frequency (percentage) for categorical data. Correlations between quantitative variables were done using Spearman correlation coefficient. $p$-values less than 0.05 were considered as statistically significant.

\section{Results}

Forty five eyes were successfully attached following RD surgery and were enrolled in the study. 


\section{Surgical outcome:}

- Forty-three eyes (95.6\%) achieved complete postoperative reattachment with Single Operation Success Rate (SOSR) Fig. (1).

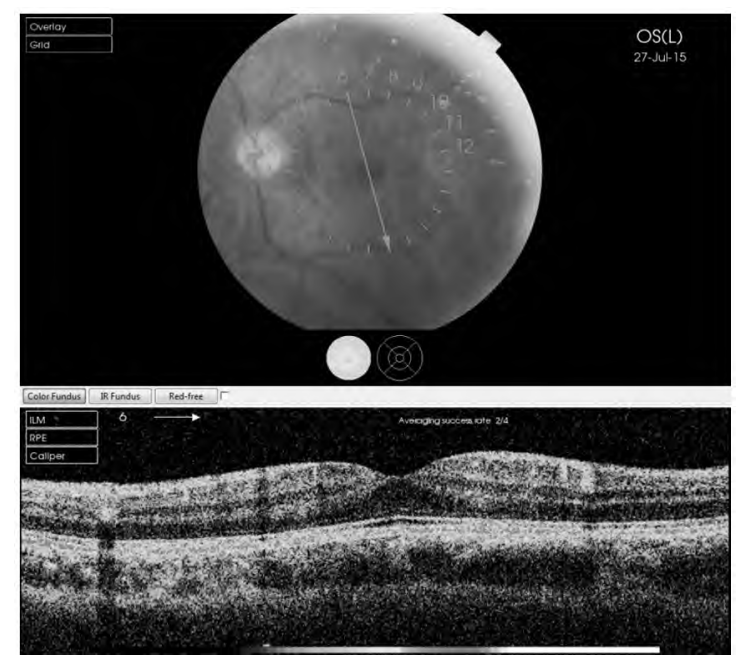

Fig. (1): Colored fundus photography and SD-OCT image showing reattached retina of the left eye following vitrectomy surgery.

- Two eyes (4.4\%) showed juxtafoveal lamellar macular hole post vitrectomy surgery evident by OCT imaging Fig. (2).
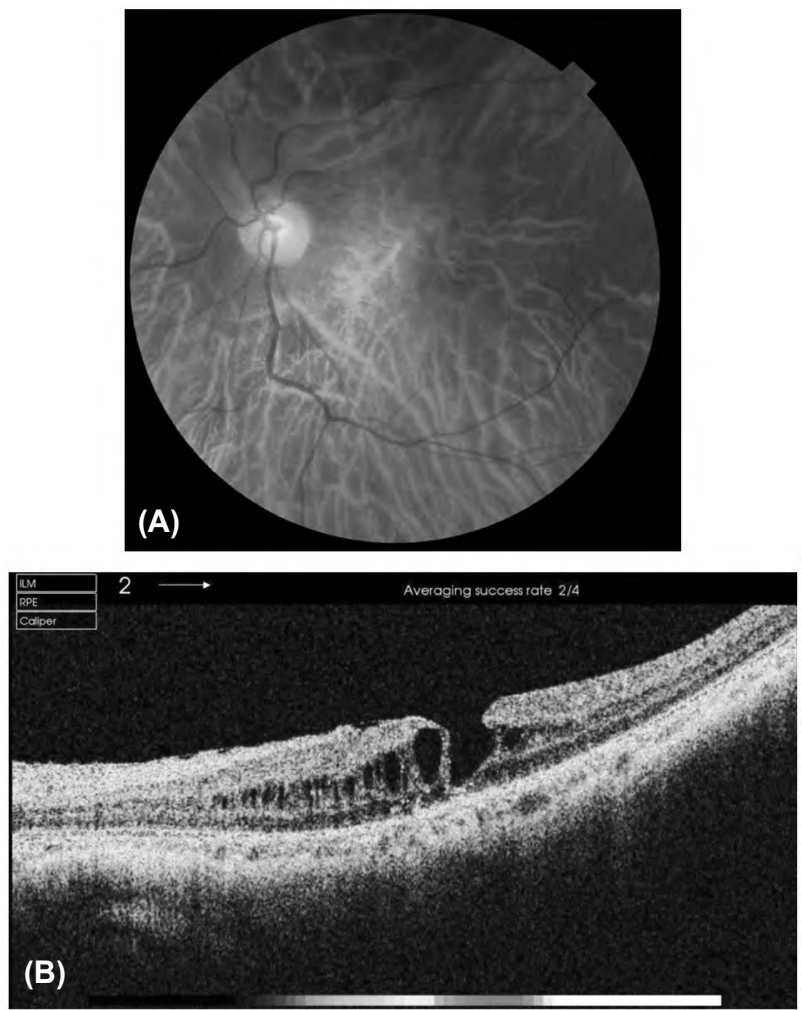

Fig. (2): (A) Colored fundus photography showing reattached retina of the left eye. (B) SD-OCT scan showing juxtafoveal partial thickness macular hole of the same eye.
Visual outcome:

Mean post-operative $\log$ MAR BCVA was 0.93 0.42 .

SD-OCT parameters evaluation following surgery:

Retinal thickness map ILM-RPE using radial scan macula: $6.0 \mathrm{~mm}-102412$ revealed:

A- Central Foveal Thickness (CFT): CFT ranged from 81 to 401 microns with a mean of 270.80 74.05 microns. CFT showed no significant correlation with postoperative BCVA $(r=0.242$, $p=0.109$ ).

$B$ - Average thickness: The average thickness ranged from 140.6 to 388 microns with a mean of 250.3962 .31 microns.

C-Macular edema: Nighteen eyes showed macular edema (intraretinal fluid) (42.2\%).

Sixteen eyes showed diffuse macular edema (35.6\%); 6 of which showed CME, and three eyes showed fovea sparing macular edema (6.6\%) in which 2 eyes showed CME. In total 8 cases showed CME. The values of BCVA showed statistically significant difference between patients with macular edema and those without $(p=0.012)$.

D- Persistent SRF: Six eyes showed persistent subretinal fluid $(13.3 \%)$.

The values of BCVA showed statistically significant difference between patients with SRF and those without ( $p=0.027)$.

E-RPE-choriocapillaries complex irregularity: Sixteen eyes showed RPE-choriocapillaries complex irregularity (36.6\%) the values of BCVA showed statistically significant difference between patients with RPE-choriocapillaries complex irregularity and those without ( $p=$ $0.005)$.

F- IS/OS junction disruption: Thirty one eyes showed IS/OS junction disruption (68.9\%).

The values of BCVA showed statistically significant difference between patients with IS/OS junction disruption and those without ( $p=0.049$ ).

$G$-Neurosensory detachment: Eleven eyes showed neurosensory detachment $(24,5 \%)$.

The values of BCVA showed statistically significant difference between patients with neurosensory detachment and those without ( $p=0.004)$.

$H$ - Epiretinal Membrane (ERM): Fourteen eyes showed epiretinal membrane (31\%). 
ERM showed no statistical significance with $\log$ MAR BCVA values $(p=0.829)$.

Interpretation of FAF macular imaging following surgery:

-Hyper-autofluorescence: Eighteen eyes showed hyper-autofluorescence at the macula $(40 \%)$. The values of BCVA showed statistically significant difference between patients with hyper-autofluorescence and those without ( $p=0.015)$.

- Hyper-autofluorescence showed statistically significant association with several OCT parameters such as:

- Macular edema $(p=0.036)$ Fig. (3).

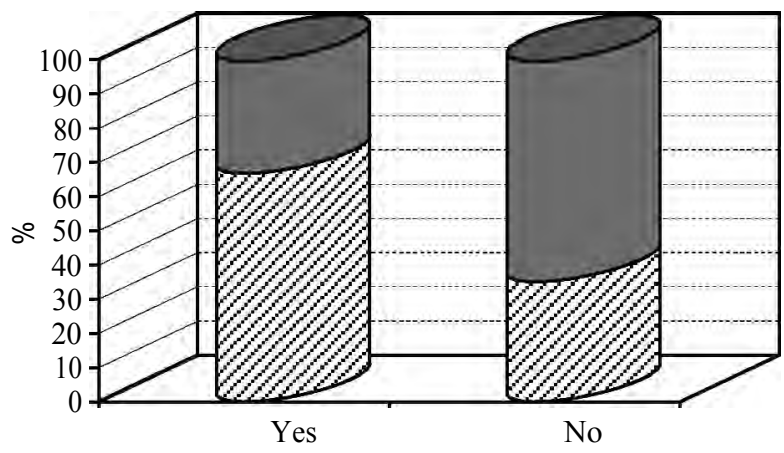

Macular edema (intraretinal fluid)

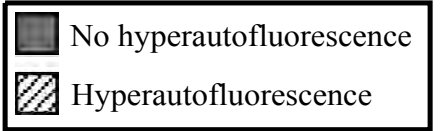

Fig. (3): Figure showing association between eyes with fundus hyper-autofluorescence and eyes with macular edema $(p=0.036)$.

- RPE-choriocapillaries complex irregularity ( $p$ $<0.001)$ Fig. (4).

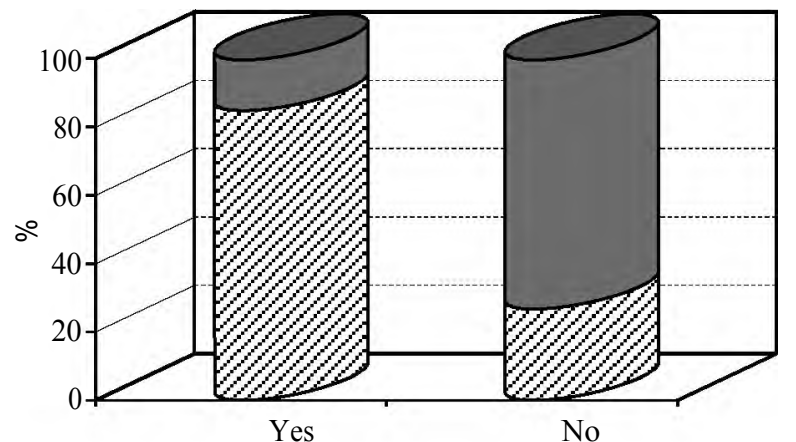

RPE-choriocapillaries complex irregularity

$\square$ No hyperautofluorescence
$E$ Hyperautofluorescence

Fig. (4): Figure showing association between eyes with fundus hyper-autofluorescence and eyes with RPEchoriocapillaries complex $(p<0.001)$.
- IS/OS junction disruption ( $p=0.018$ ) Fig. (5).

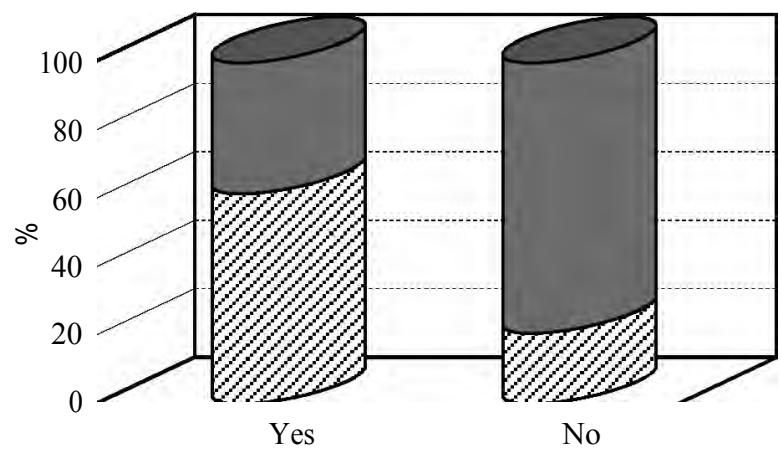

IS/OS segment disruption

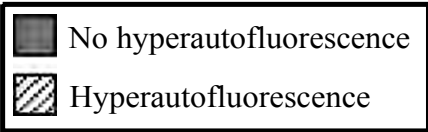

Fig. (5): Figure showing association between eyes with fundus hyper-autofluorescence and eyes with IS/OS junction disruption $(p=0.018)$.

- Neurosensory detachment ( $p=0.016)$ Fig. (6).

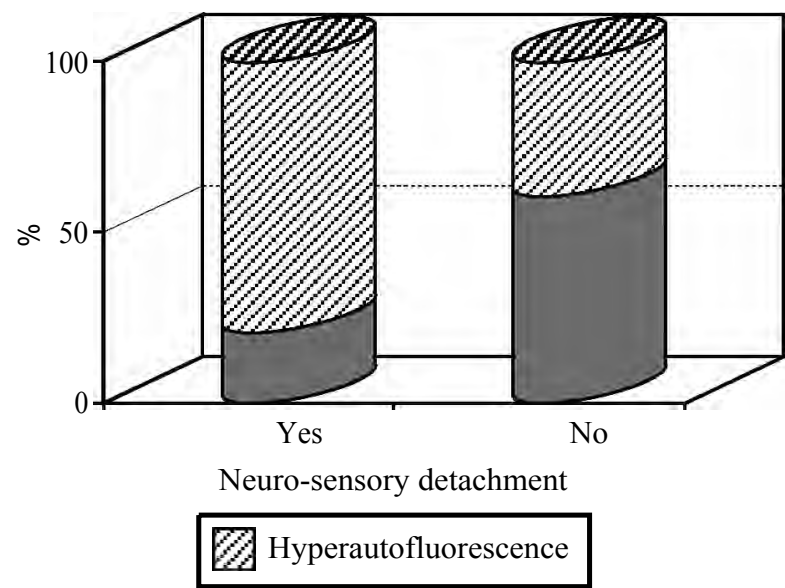

Fig. (6): Figure showing association between eyes with fundus hyper-autofluorescence and eyes with neurosensory detachment $(p=0.016)$.

\section{Discussion}

Incomplete visual recovery after anatomically and clinically successful repair has been attributed to several pre-operative and post-operative factors. Several studies analyzed the pre-and post-operative factors in order to identify the factors that could potentially affect the post-operative functional outcome [1]

In our prospective study, we analyzed the relationship between the post-operative SD-OCT scans and FAF imaging findings. This helped us to evaluate the micro-anatomical structural abnormalities of the macula that could affect the final visual function. 
We chose a cross sectional analysis of the retinal structure starting 4 weeks post-operative, as it is usually the time by which retinal structures start to stabilize and optical media become clear [2] .

Tsilimbaris and associates [3], noted that cystoid macular edema appears to be the most frequent post-operative macular complication associated with poor visual outcome. Their study concluded that the anatomical changes at the level of the macula are mostly the reason of poor visual recovery after successful RD surgery. In our study 19 eyes $(42.2 \%)$ showed macular edema detected by OCT imaging, in which 8 eyes (17.6\%) showed CME. The values of BCVA showed statistically significant difference between patients with macular edema and those without ( $p=0.012$ ).

We evaluated the relationship between the central foveal thickness and the post-operative visual outcome. No correlation was found between CFT and BCVA $(r=0.242, p=0.109)$.

Studies have shown that clinically invisible pockets of SRF may persist subfoveally on OCT several weeks after successful vitrectomy surgery. Persistent SRF was associated with poor visual outcome [4].

In our study, OCT imaging revealed persistent pockets of subretinal fluid in six eyes (13.3\%) after vitrectomy surgery. The values of BCVA showed statistically significant difference between patients with SRF and those without ( $p=0.027)$.

Another factor that was suggested to decrease the visual acuity was the formation of postoperative epiretinal membrane with or without spongiform macular thickness. ERM may cause distortion and contraction of the retinal layers [1]

Tsilimbaris and colleagues [3], observed that presence of ERM in OCT without a significant alteration in foveal thickness does not necessarily predetermine a low visual acuity. In our study 14 eyes $(31 \%)$ showed epiretinal membrane with wrinkling of the inner retinal layers without affecting the CFT. Eyes with ERM showed no statistical significance with BCVA values $(p=0.829)$.

Post-operative foveal detachment is another OCT finding affecting the visual outcome despite clinically attached retina. In our study 11 eyes $(24.5 \%)$ showed shallow foveal neurosensory detachment. The values of BCVA showed statistically significant difference between patients with neurosensory detachment and those without ( $p=0.004)$. Our result is consistent with the study done by Hagimura and colleagues [5].
A less frequent pathology related to poor visual outcome is the macular atrophic changes and the development of a macular hole during or immediately after RRD surgery [3] . Our data analysis suggests that three such eyes were found in the study with low visual acuity after RRD repair. One eye revealed macular atrophic changes $(2.2 \%)$ and 2 eyes revealed juxtafoveal macular hole (4.4\%).

Even if all the evident changes that alter the foveal contour or thickness were absent on OCT, patients may also present with impaired postoperative visual acuity. Impaired visual acuity could be explained by photoreceptor (cone) atrophy or non-integrity. The integrity of the cone OSs in the macular region could serve as a marker of cones health, the cells primarily responsible for visual acuity [6].

Recent advances in imaging technologies have allowed us to detect ultrastructural abnormalities in the macula to histological details and to correlate these changes with functional deficits. SD-OCT can clearly delineate the retina into its individual layers by eliminating motion artifacts. Structures like IS/OS junction of the photoreceptors can be easily detected especially in the grey scale image [7].

It was found that almost immediately after detachment of the retina, photoreceptor degeneration and outer segment length reduction occurs. Apoptotic changes also occur soon after detachment, and are followed by the progressive loss of photoreceptors if left untreated. Incomplete recovery of vision may therefore ensue, despite a normallooking retina. On OCT, this could be manifested by the disruption of inner segment/outer segment junction [6]

Disruption of the IS/OS junction despite successful RRD repair ranges from 43 to $83 \%$. Apparently, IS/OS junction disruption was significantly more common when the macula was pre-operatively detached [7]. Although disruption rates may vary over different series, vision in general was significantly poorer with a disrupted IS/OS junction.

Our study was consistent with previously mentioned studies, where 31 eyes revealed IS/OS junction post-operative disruption and the values of BCVA showed statistically significant difference between patients with IS/OS junction disruption and those without $(p=0.049)$.

Clinical studies have proved that visual function can be related to SD-OCT changes in the outer retinal layers. Our hypothesis suggests that there 
may be an association between FAF changes and morphological and visual outcome. In our study we observed the autofluorescent changes at the macula and correlated these changes with postoperative BCVA and OCT findings.

FAF imaging is able to map metabolic changes at the level of the Retinal Pigment Epithelium (RPE) noninvasively in vivo. However, the observed autofluorescence signal is a summation of not only the autofluorescence originating from the RPE but also that from more anterior ocular structures including the overlying neuroretina [8]

Increased levels of AF indicate increased presence of oxidative stress and increased metabolic activity as the RPE enters a preapoptotic state. Therefore, AF is a valuable modality for assessing the function of RPE cells and the viability of the retinal function [9]

Another suggested pathogenesis of hyperautofluorescence following RRD repair was outer retinal disruption. This might result in increased autofluorescence due to a window defect as a result of photopigment loss over an intact RPE. Recognizing that increased FAF can occur in the absence of increased fundus fluorophores may help clinicians to detect and more precisely monitor early photoreceptor damage. In some patients, these findings may provide an anatomical correlate of persistent suboptimal visual function despite relatively normal RPE structure [10].

Witmer and associates [2], used the Ultra Wide Field AF (UAF) to assess patients with RRD before and after surgical repair in order to determine AF abnormalities and correlated the findings with SDOCT images. Other reports investigating AF abnormalities in RRD have focused on the central macular area [7]

In our study 18 eyes (40\%) showed evident postoperative hyper-autofluorescent changes. The values of BCVA showed statistically significant difference between patients with hyperautofluorescence and those without $(p=0.015)$; which coincides with the results of Witmer and associates [2] $(p=0.09)$.

Several characteristics were present in eyes showing hyper-autofluorescence in the form of residual line of AF demarcation, hyper-autofluorescent changes adjacent to retinal vessels, hyperautofluorescent macular changes due to pathology, granular AF changes in the macula, and residual hyper-autofluorescence after scleral buckling procedure.
FAF characteristics were analyzed simultaneously with OCT that permitted to acquire pathologic data in vivo showing that macular edema, persistent foveal detachment, distortion, disruption of Outer Retinal Layers (ORLs) and Outer Retinal Folds (ORFs) are common findings consisting with hyperautofluorescence following successful surgery for retinal detachment [11]

In our study, sixteen eyes (36.6\%) showed RPEchoriocapillaries complex irregularity (ORFs) by OCT. Simultaneous AF imaging showed areas of diffuse macular hyper-autofluorescence (RPE stress cells). Statistical analysis showed significant association between eyes with fundus hyper-autofluorescence and eyes with RPE irregularity $(p<0.001)$.

A residual line of demarcation was frequently located in the location of the prior HLE (hyperautofluorescent leading edge). The HLE likely represents the collection of fluorophores from photoreceptor outer segments, which have been shed and are collecting in the subretinal space; It may also represent RPE cells with increased metabolic activity due to the stress at the border of attached and detached retina [2]

Our results showed one eye with evident residual demarcation line by FAF imaging. A hyperautofluorescent line (Demarcation line) was frequently located postoperatively and may coincide with shallow neurosensory detachment by OCT [2] . In our study, 11 eyes showed shallow neurosensory detachment by OCT. Neurosensory detachment cases showed significant association with macular hyper-autofluorescence $(p=0.016)$.

Two eyes in the study demonstrated hyperautofluorescent lines parallel to the retinal vessels postoperatively. This is similar to the phenomenon described in the report by Shiragami and colleagues [12] . As suggested in the report, these hyperautofluorescent lines may develop because the retina is reattached in a slightly different position postoperatively than where it had been before the retinal detachment (post-operative retinal translocation).

The hyper-autofluorescent lines would originate from increased metabolic activity of the RPE that was pre-operatively located under the retinal vessels and is post-operatively exposed to light because of displacement of the retina.

Shiragami and colleagues [12], proposed to call these lines "Retinal Vessels Printings" (RVPs) because they closely resemble the retinal vessels 
they are related to. OCT sections of these lines do not reveal characteristic features.

Eight eyes in our study demonstrated cystoid macular edema by OCT Scan and exhibited hyperautofluorescent patches in the macula postoperatively. Significant association was found between eyes with fundus hyper-autofluorescence and eyes with macular edema $(p=0.036)$.

The intensity of AF changes depends upon the status of the overlying retina because AF generated by the RPE cells travels through the sensory retina. Hyper-autofluorescence, therefore, may also result from increased transmission due to retinal atrophy [8]. In our study one patient revealed atrophic macular thickness by OCT (CFT $\pm 80 \mathrm{um})$ and simultaneous macular hyper-autofluorescence by FAF imaging.

Post-operative AF imaging was obtained in one eye that had repair of RRD with a scleral buckle. One month post-operative, this eye demonstrated shallow residual subretinal fluid clinically and hyper-autofluorescence in the same location. AF imaging was particularly useful postoperatively in detecting the presence of subretinal fluid and delineating its borders. This imaging modality may be useful in monitoring the resorption of subretinal fluid after scleral buckling procedures.

OCT imaging of eyes showing IS/OS junction disruption consisted with diffuse granular hyperautofluorescent changes post-operatively. Statistical analysis revealed association between eyes with fundus hyper-autofluorescence and eyes with IS/OS junction disruption $(p=0.018)$.

FAF patterns have been significantly correlated with SD-OCT findings in 2 studies involving successfully repaired RRD cases that were followedup for up to 10 months postoperatively. Studies done by Lai et al., [7] and Witmer et al., [2], showed that the disruption of the inner segment/outer segment junction correlated well topographically with FAF defects in those who had poor visual outcomes ( $p=0.04$ and $p=0.09$ respectively).

However, in another series by Dell'Omo and associates [11], where successfully repaired RRD patients were followed for up to 2 years postoperatively, such correlation was not found.

Limitations of this study include the relatively small sample size, and the lack of pre-operative imaging for comparison. The short follow-up period (6 months to 1 year) didn't allow for serial imaging to be performed in all our patients to examine the extent of restoration of the outer retinal layers and the changes in FAF over time.

\section{Conclusion:}

Incomplete visual recovery after anatomically and clinically successful repair of RRD is attributed to several factors. The IS/OS junction disruption, persistent SRF, macular edema, neurosensory detachment and RPE-choriocapillaries complex irregularity are considered vital measures affecting the structure and function of the macula and can explain the incomplete visual recovery following a successful RD surgery.

SD-OCT is considered a valuable, non-invasive tool for evaluating the previously mentioned microstructural changes. Fundus autofluorescence is a recent valuable, non-invasive imaging technique; it detects the function and health of the photoreceptor and the RPE layers showing great advantage in analyzing the macular function abnormality.

\section{References}

1- NAKANISHI H., HANGAI M., UNOKI N., et al.: Spectral-domain optical coherence tomography imaging of the detached macula in rhegmatogenous retinal detachment. Retina, 29: 232-42, 2009.

2- WITMER M.T., CHO M., FAVARONE G., et al.: Ultrawide-field autofluorescence imaging in non-traumatic rhegmatogenous retinal detachment. Eye (Lond), 26: 1209-16, 2012.

3- TSILIMBARIS M.K., CHALKIA A., TSIKA C., et al.: Clinical and spectral-domain optical coherence tomography findings of patients with incomplete visual recovery after anatomically successful retinal detachment surgery. J Ophthalmol., Article ID 420401, 5 pages, 2015.

4- BENSON S.E., SCHLOTTMANN P.G., BUNCE C., et al.: Optical coherence tomography analysis of the macula after vitrectomy surgery for retinal detachment. Ophthalmology, 113: 1179-83, 2006.

5- HAGIMURA N., IIDA T., SUTO K., et al.: Persistent foveal retinal detachment after successful rhegmatogenous retinal detachment surgery. Am. J. Ophthalmol., 133: 51620, 2002.

6- SHETH S., DABIR S., NATARAJAN S., et al.: Spectral domain-optical coherence tomography study of retinas with a normal foveal contour and thickness after retinal detachment surgery. Retina, 30: 724-32, 2010.

7- LAI W.W., LEUNG G.Y., CHAN C.W., et al.: Simultaneous spectral domain OCT and fundus autofluorescence imaging of the macula and microperimetric correspondence after successful repair of rhegmatogenous retinal detachment. Br. J. Ophthalmol., 94: 311-8, 2010.

8- SCHMITZ-VALCKENBERG S., HOLZ F.G., BIRD A.C., et al.: Fundus autofluorescence imaging: Review and perspectives. Retina, 28: 385-409, 2010.

9- LOIS N. and FORRESTER J.V.: Fundus Autofluorescence. Philadelphia, PA: Lippincott Williams and Wilkins, 2009. 
10- FREUND K.B., MREJEN S., JUNG J., et al.: Increased fundus autofluorescence related to outer retinal disruption. J.A.M.A. Ophthalmol., 131: 1645-9, 2013.

11- DELL'OMO R., MURA M., LESNIK OBERSTEIN S.Y., et al.: Early simultaneous fundus autofluorescence and optical coherence tomography features after pars plana vitrectomy for primary rhegmatogenous retinal detachment. Retina, 32: 719-28, 2012.

12- SHIRAGAMI C., SHIRAGA F., Y AMAJI H., et al.: Unintentional displacement of the retina after standard vitrectomy for rhegmatogenous retinal detachment. Ophthalmology, 117: 86-92, 2010.

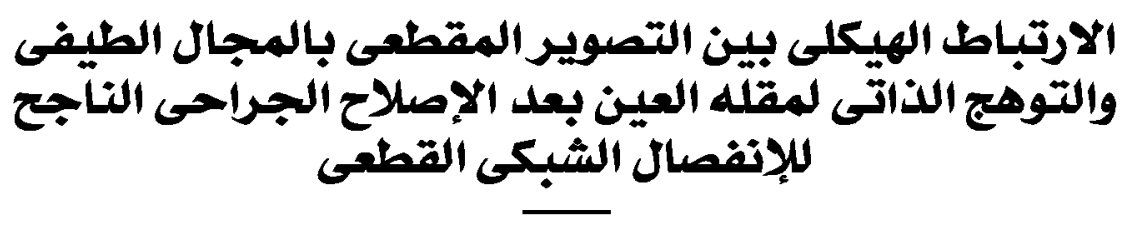

يؤدى إنفصال الشبكية القطعى إلى التشتت التشريحى لثبكية العين، وبالتالى إلى قصود فى حدة الإبصار. ورغم معدلات النجاح الجراحى والتشريحى الممتازة مع طرق العلاج العائدة، لا زالت نتائج حدة الإبصار غير مرضية فى بعض الحالات. ويعتبر (المسبح المقطعى الضوئى بالمجال الطيفى) وبسلة هامة لتشخيص ورصد ومتابعة كل آمراض مركز الإبصار. هذه الوسيلة قادرة

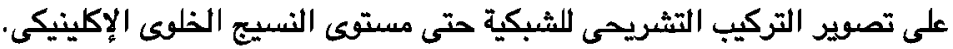

ويعد (التوهج الذاتى لقاع العين) وبسيلة تصوير غير غازية قادرة على تقييم الحالة الوظيفية والتشريحية للشبكية. الهدف من هذه الدراسة هو بحث العلاقة التركيبية الوظيفية لمركز الإبصار عن طريق إيجاد العلاقة بين نتائج (التوهـج الذاتى لقاع العين) \& (المسع المقطعى الضوئى بالمجال الطيفى) وحدة الإبصار النهائية، وذلك بعد إجراء جراحة إصلاح ناجحة للإنفهال الشبكى القطعى. وآجرى التصوير لقاع العين بالوسيلتين في خلال مدة من شهر إلى ثلاثة آثهر عند ثبات حالة الثبكية بعد الجراحة. ويعزى علم إستعادة كفاءة حدة الإبصار بعد النجاح التشريحى والإكلينيكى لجراحة الإنفصال الثبكى القطعى إلى عدة آسباب. وبينت الدراسة آن هناك إختلافا جوهريا بين متوبط حدة الإبصار قبل وبعد الجراحة. وآثثتت التحاليل الإحصائية وجود علاقة جوهرية

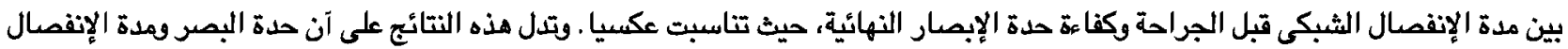

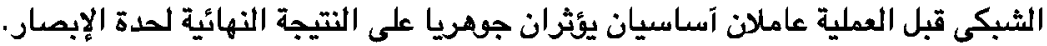

بينت الدراسة آن هناك فرقا جوهريا في حدة الإبصار النهائية بين الصالات التى آظهر فيها (المسع المقطعى الضوئي بالمجال الطيفى)

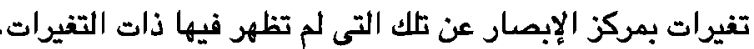

وكذلك بينت هذه الدراسة آن هناك فرقا جههريا فى حدة الإبصار النهائية بين الحالات التى ظهر بها زيادة في التههج الذاتى لمركز الإبصار عن تلك التى لم يظهر بها زيادة في هذه التورهـ

وآثتبتت الدراستة وجود توافق جوهرى بين زيادة التوهـع الذاتى لقاع العين والتغيرات التى آظهرها (المسبح المقطعى الضوئى بالمجال الطيفى) لمركز الإبصار

ويعد فحص شبكية العين بواسطة التوهـ الذاتى وسيلة حديثة قيمة غير غازية، تقيم الوظيفة والتناسق المستقبلات الضوئية والطبقات الخارجية الصبغية للشبكية. وتعد هذه الوبسيلة ذات ميزة كبيرة في تحليل إختلال وظائف مركز الإبصار. 